
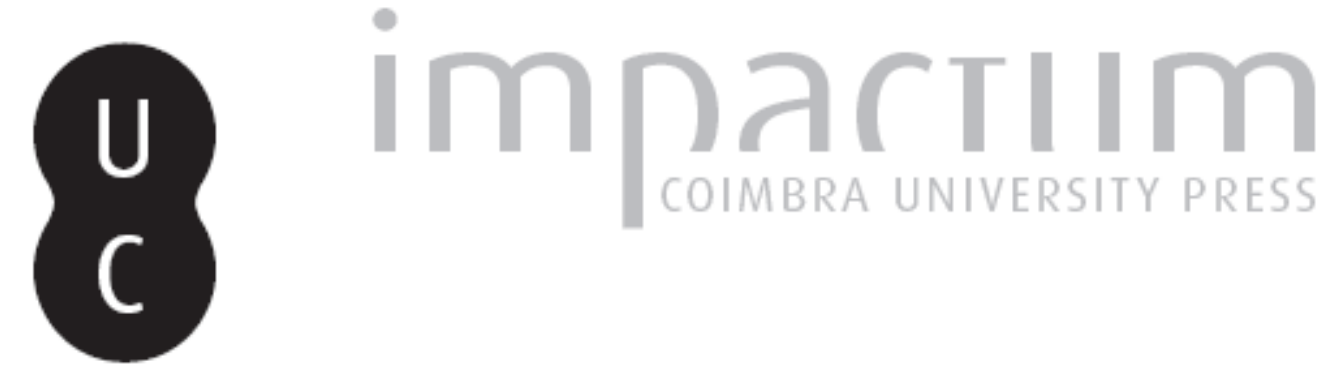

\title{
Herencia de una industria entre dos orillas: las dimensiones de las Fábricas de Tabacos en España: identidad de un patrimonio industrial arquitectónico a través de la mirada contemporánea
}

\author{
Autor(es): $\quad$ Castañeda López, Carolina \\ Publicado por: Editorial do Departamento de Arquitetura \\ URL \\ persistente: \\ URI:http://hdl.handle.net/10316.2/39946 \\ DOI: \\ DOI:https://doi.org/10.14195/1647-8681_6_12
}

Accessed : $\quad$ 26-Apr-2023 16:01:43

A navegação consulta e descarregamento dos títulos inseridos nas Bibliotecas Digitais UC Digitalis, UC Pombalina e UC Impactum, pressupõem a aceitação plena e sem reservas dos Termos e Condições de Uso destas Bibliotecas Digitais, disponíveis em https://digitalis.uc.pt/pt-pt/termos.

Conforme exposto nos referidos Termos e Condições de Uso, o descarregamento de títulos de acesso restrito requer uma licença válida de autorização devendo o utilizador aceder ao(s) documento(s) a partir de um endereço de IP da instituição detentora da supramencionada licença.

Ao utilizador é apenas permitido o descarregamento para uso pessoal, pelo que o emprego do(s) título(s) descarregado(s) para outro fim, designadamente comercial, carece de autorização do respetivo autor ou editor da obra.

Na medida em que todas as obras da UC Digitalis se encontram protegidas pelo Código do Direito de Autor e Direitos Conexos e demais legislação aplicável, toda a cópia, parcial ou total, deste documento, nos casos em que é legalmente admitida, deverá conter ou fazer-se acompanhar por este aviso.

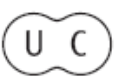




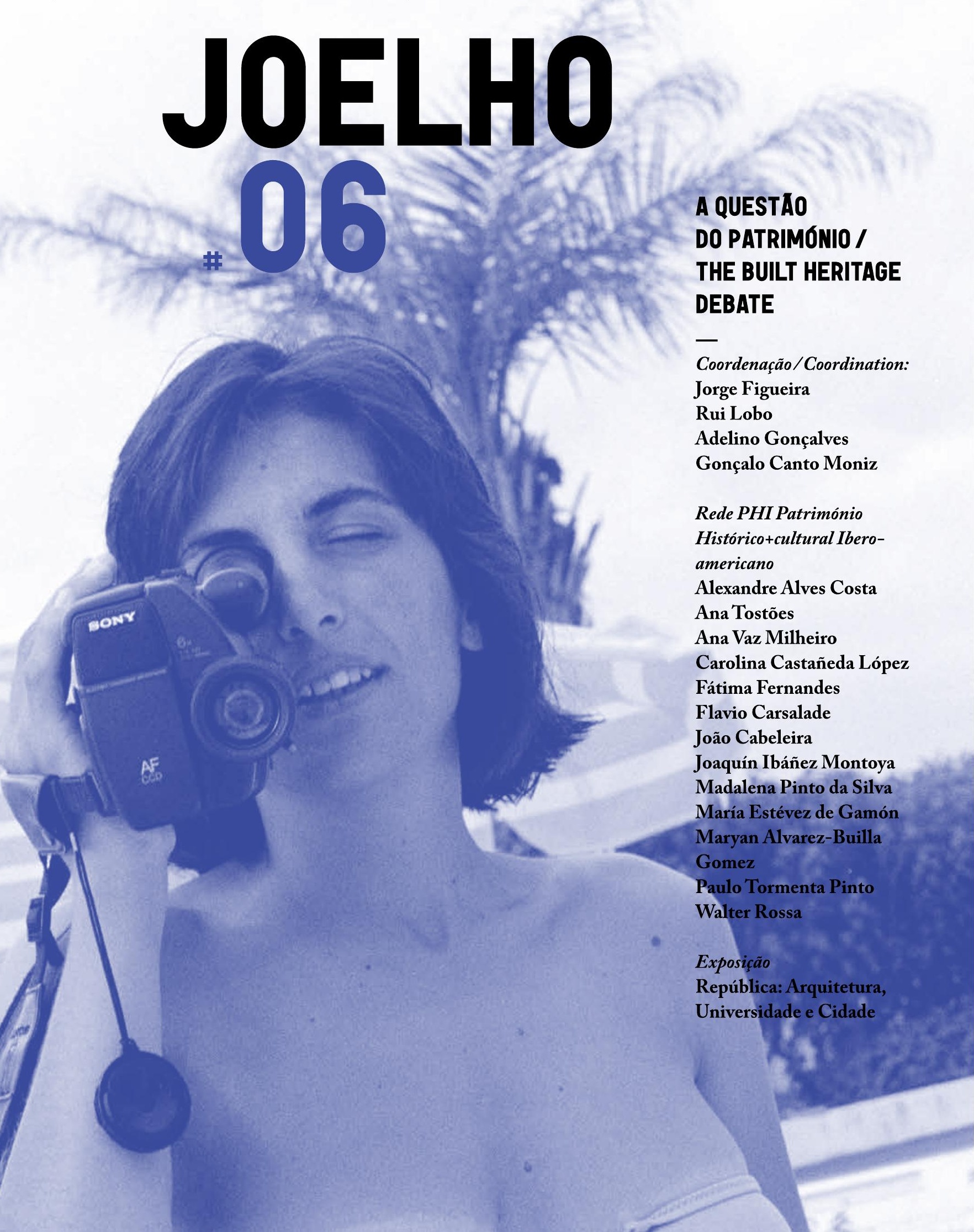




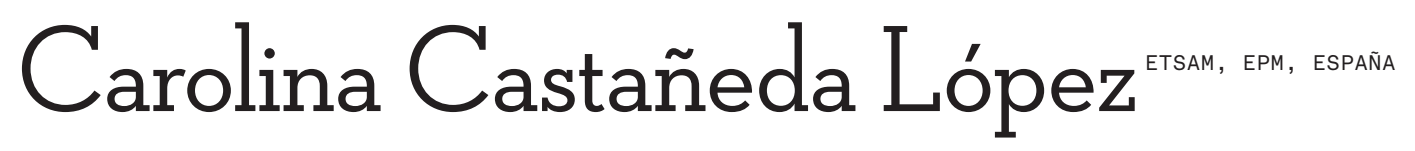
I-Ierencia de una industria entre dos orillas. I as dimensiones de las Fábricas de 'T'abacos en Eispaña: identidad de un patrimonio industrial arquitectónico a través de la mirada contemporánea 
Tomando como modelo la tipología de fábrica manufacturera francesa de iniciativa real, las Reales Fábricas españolas comenzaron a instaurarse en la geografía peninsular en el s.XVII como industrias productoras de bienes cuya renta resultaba muy beneficiosa para la Corona. El caso particular de las Reales Fábricas de Tabacos conformó una realidad laboral e industrial muy especial centrada en la figura femenina, que realizaba la práctica totalidad de las labores.

La importación del tabaco desde las colonias americanas y el inicio de su consumo, constituyeron el origen de la creación de factorías de producción tabacalera controladas por la Corona, que instauró un régimen hacendístico especial con el establecimiento del Estanco del Tabaco en el S.xviI (Rodríguez Gordillo, 2002). La producción tabacalera en España se consolidó a raíz del citado monopolio reportando beneficios directos a la Real Hacienda por su gravación como producto suntuario. El aumento de su consumo entre la población, junto a los problemas generados por el contrabando, provocó la expansión periódica de establecimientos tabacaleros en la península, desde la pionera de Sevilla del S.XVIII, hasta las más tardías de Tarragona y Málaga del primer tercio del pasado siglo.

La privatización del sector a finales del s.xx supuso el cierre de la mayor parte de las tabacaleras centenarias remanentes que constituían una rémora para la producción, dejando en el paisaje urbano espacios abandonados que pasarían a valorarse por sus cualidades histórico-culturales (Campos Luque, 2004). El estudio de estos vestigios tabacaleros como patrimonio industrial arquitectónico viene caracterizado por los diversos campos de interés que conforman su casuística particular en su interpretación a través de la mirada contemporánea en la que se imbrican sus dimensiones territorial y urbana, arquitectónica, topológico-productiva y humana, propias de la realidad multiescalar de este conjunto de bienes patrimoniales industriales.

\section{La dimensión territorial y urbana: el comercio marítimo colonial como hilo conductor de la expansión geográfica}

El comercio marítimo tabacalero surgido de la relación con las colonias americanas hizo que muchas ciudades portuarias españolas prosperasen sobre todo a partir de 1636, año en que se establece el Estanco del Tabaco y se regula su comercialización como medio de obtención de ingresos para la Corona. Sevilla se instauró como el puerto principal desde el que se distribuía el producto venido de las Américas, pero otras muchas plazas fueron adquiriendo entidad en la recepción y distribución de la hoja de tabaco. Será con el establecimiento de la Real Hacienda como administrador directo del monopolio en 1730, cuando se vea necesaria la creación de centros de producción específicos en las ciudades a las que llegaba el producto, dado que el contrabando vigente en los puertos hacía peligrar los cuantiosos beneficios tributarios generados con la venta del tabaco.

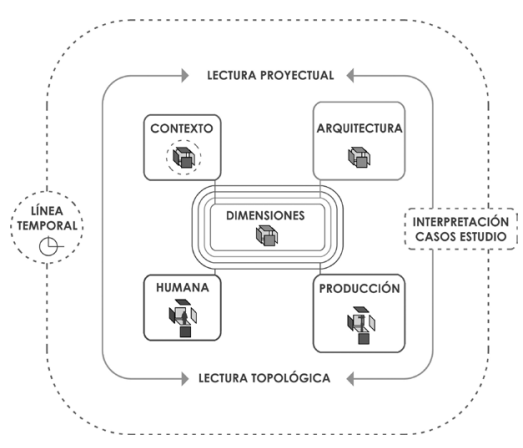

1. Aspectos tratados en la argumentación. Fuente: elaboración propia (2015). 
2. Distribución geográfica de los casos de estudio abordados en la investigación. Fuente: elaboración propia (2015).

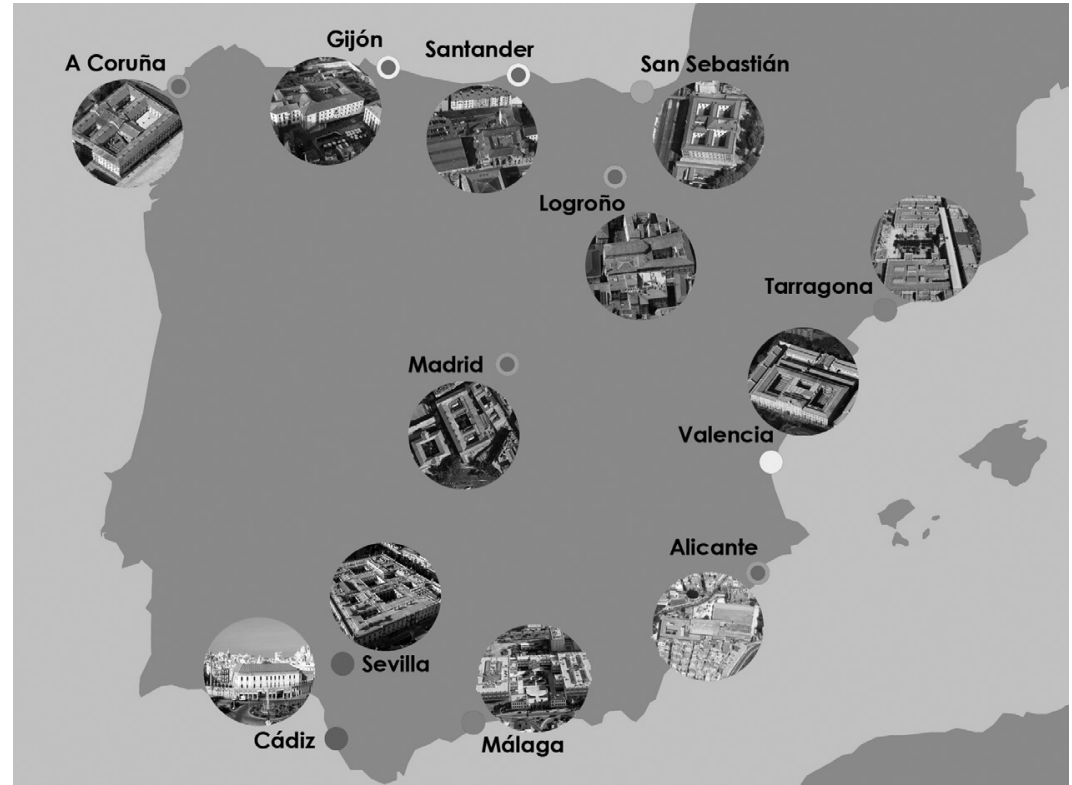

Finales S.XVIII

Primera generación S.XIX

Segunda generación S.XIX
Tercera generación S.XIX

Principios S.XX

Edificios reutilizados

Para ello se establecieron una serie de enclaves portuarios en los que se descargaba la materia prima importada de Cuba, Brasil y Estados Unidos. De esta forma, a lo largo del s.XIX se produjo una expansión geográfica de la producción tabacalera en una serie de generaciones de fábricas, ubicadas funcionalmente en urbes con puerto de mar o fluvial y en localidades distanciadas entre sí, facilitando el abastecimiento de las factorías y optimizando la distribución posterior a las expendedurías locales. De esta forma, se trataba de consolidar y organizar una realidad informal surgida de la elaboración clandestina del producto tabacalero en los enclaves portuarios receptores de hoja de tabaco - como Alicante, A Coruña o Gijón - y se sentaban las bases para un dominio territorial de la producción y comercio que ostentaba la Renta del Tabaco.

La industria del tabaco y la cercanía al puerto supusieron el hilo conductor de la estrategia de ubicación de las tabacaleras, generando una relación dialéctica entre la fábrica y el espacio portuario a través de las redes industriales de circulación de producto que condicionaron en gran parte el tejido urbano afectado. Esta posición de centralidad urbana de las fábricas de tabacos proporcionaba una localización de relevancia por su cercanía a los principales órganos de autoridad de las urbes en las que se ubicaban y facilitaba el desplazamiento de las mujeres a las que empleaba. De igual forma, la frecuente falta de espacio en las propias fábricas conllevaba a la búsqueda de locales de almacenaje externos en la ciudad ampliando su interacción con el tejido urbano más allá de los límites del conjunto fabril. 
Por otra parte, las tabacaleras marcaban el ritmo del barrio en el que se ubicaban y establecían unas peculiares condiciones de borde con su entorno. Los nuevos establecimientos surgidos a partir de las últimas décadas del S.XIX se alejan progresivamente del centro urbano siguiendo los preceptos higienistas de la época; no obstante, la expansión de las ciudades en el S.XX, terminó fagocitando estas fábricas inicialmente periféricas, convirtiéndolas en un elemento urbano representativo más del tejido consolidado.

\section{La dimensión arquitectónica: los invariantes de la arquitectura fabril tabacalera en España}

La falta de modelos en la concepción de una arquitectura propia de la actividad industrial en las primeras fábricas conllevó a la reproducción de esquemas espaciales anteriores sin crear un orden arquitectónico nuevo. La total falta de referentes culturales inducía a una búsqueda de soluciones en otras tipologías y en la reutilización de modelos anteriores para la nueva función industrial que, junto al lenguaje académico y racionalista propio de la ideología del despotismo ilustrado, convertían las primeras arquitecturas fabriles en un laboratorio de soluciones que bebía del lenguaje arquitectónico culto y de la experiencia de la ingeniería militar (Hernando, 1989, pp. 353-371).

Tal es el caso de las Fábricas de Tabacos en España cuyo estudio como patrimonio industrial arquitectónico viene caracterizado por una doble lectura proyectual-arquitectónica y topológica-productiva en el análisis particular del desarrollo y evolución histórica de estas arquitecturas. Pese a su variada casuística, las tabacaleras españolas poseían una serie de invariantes comunes en relación a las cualidades arquitectónicas y espaciales en las que se desarrollaba la producción.

En términos proyectuales, la arquitectura industrial tabacalera se caracterizó por una tensión dialéctica entre el carácter representativo de la fachada y la mutabilidad del interior, sujeto a los cambios propios de la organización productiva. Esta doble condición se manifestó en la preocupación estética propagandística de la envolvente exterior a través de un lenguaje arquitectónico anacrónico, solemne y culto, expresión del gusto estilístico de la época o de las tendencias regionalistas del lugar. Sin embargo, la realidad interior de constante mutabilidad sometida a los cambios organizativos de la producción y a la evolución de una industria manufacturera hacia la mecanización de todas las fases de elaboración, generó una suerte de maridaje estilístico que se mantendría como aspecto intrínseco propio de la arquitectura fabril tabacalera (Koolhaas, 1978, p. 100) ${ }^{1}$.

Los inmuebles que albergaron la actividad productiva del tabaco se materializaron según una configuración claustral en torno a patios que constituía el principio ordenador del conjunto, proporcionando luz y ventilación al interior de los talleres. Estos constituían la unidad básica espacial del ámbito productivo, que se contraponía a la función representativa de las estancias administrativas y la vivienda del

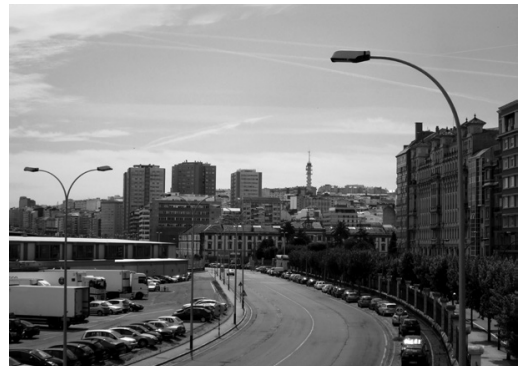

3. Fábrica de Tabacos de A Coruña como claro exponente de elemento rótula entre la periferia y el centro de la ciudad que ha propiciado la expansión y consolidación del tejido urbano. Fuente: fotografía de la autora (2014).
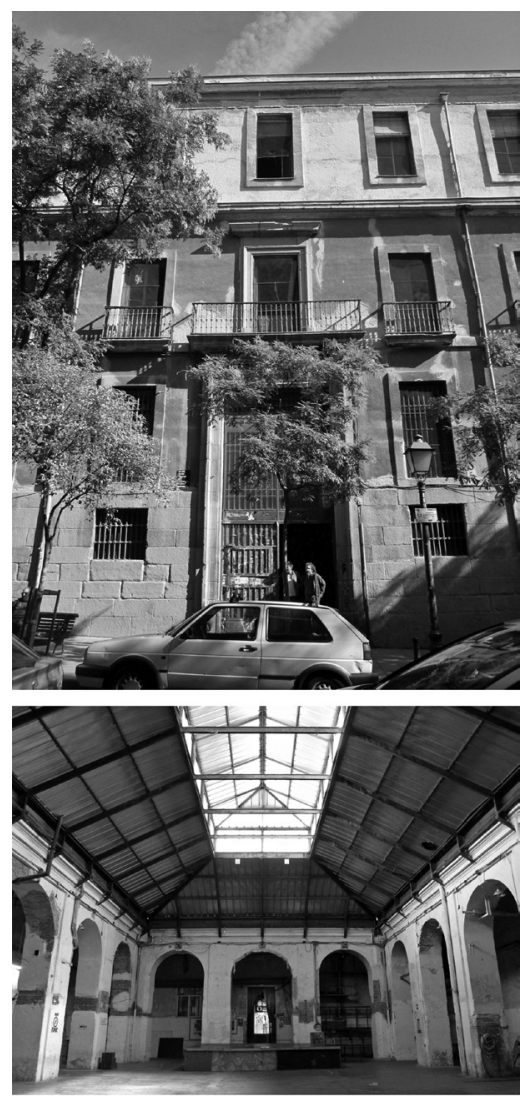

4. La fachada como elemento representativo de relación con el entorno próximo y el interior estructurado en torno a una organización claustral, en la Fábrica de Tabacos de Madrid. Fuente: fotografías de la autora (2013 y 2015). 
5. Comparación de la evolución de los modelos tabacaleros español y francés. Fuente: elaboración propia (2015).

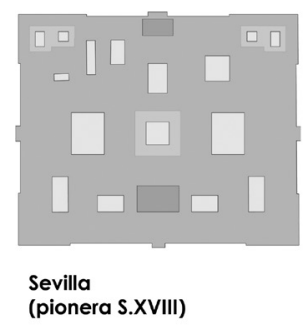

(pionera S.XVIII)

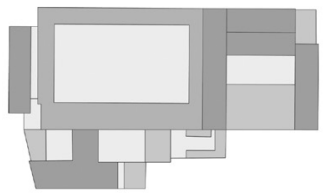

Morlaix (modelo Blondel S.XVIII)

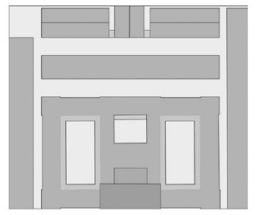

Valencia (proyecto nueva planta principios S.XX)

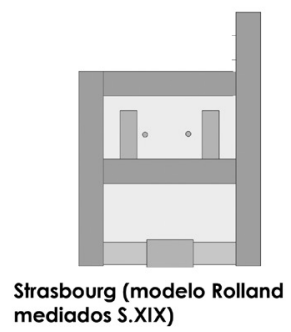

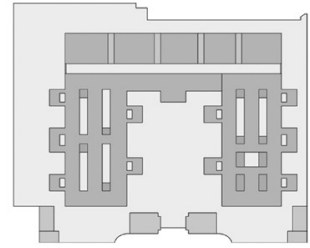

Tarragona (proyecto nueva planta principios S.XX)

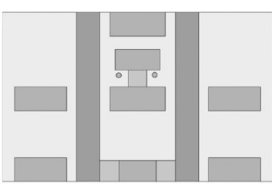

Nantes (modelo Rolland mediados S.XIX)

director, polarizando el complejo fabril. A través de esta organización claustral, se garantizaba la clausura respecto al ámbito exterior y el espacio interior se erigía como instrumento de control del operario, materializándose en un sistema de mecanismos de vigilancia similares a otros tipos de arquitecturas coercitivas como cárceles, cuarteles o conventos. La distribución en torno a patios permitía un mayor control del personal empleado, confluyendo los recorridos del mismo únicamente hacia el interior y hacia un único acceso en el que las operarias eran sometidas a un riguroso registro (Selvafolta, 1985).

Con la evolución del proceso productivo y los cambios organizativos del espacio derivados de la mecanización de la producción, el carácter compacto de las Fábricas de Tabacos en España manifestó la rigidez del edificio tabacalero en su comportamiento como unidad fabril, en contraposición a la flexibilidad característica de los modelos espaciales de las arquitecturas industriales concebidas posteriormente. La evolución de las Fábricas de Tabacos en España hacia un modelo en pabellones y con una racionalización mayor del espacio productivo, provendría del cambio conceptual de la organización de la manufactura anclada en los métodos de producción heredados del Antiguo Régimen al modelo concebido por las sociedades arrendatarias que desde finales del s.XIX ostentarían la gestión del monopolio. Sus actuaciones se encaminaron, fundamentalmente, a superar el atraso técnico del que adolecían las fábricas existentes y a iniciar la construcción de nuevas plantas fabriles acordes a una moderna producción.

Pese a que la Real Fábrica de Tabacos de Sevilla constituyó un excelente ejemplo fabril de nueva planta como establecimiento pionero en España, la producción tabacalera se adaptó frecuentemente a numerosos edificios preexistentes a la nueva actividad industrial, estableciéndose en inmuebles desafectados gracias a los procesos 
desamortizadores del S.XIX. De esta forma, mediante la reutilización de edificios preexistentes se aumentaba al máximo la rentabilidad de las tabacaleras y se disponía de un inmueble propiedad del Estado que constituía de la base espacial necesaria para su reconversión en fábrica de tabacos. La relativa facilidad para adaptar dichos contenedores a la producción manufacturera del tabaco, constituyó una circunstancia crucial en la definición de su espacialidad puesto que, en muchos casos, el "hecho reutilizador" en las tabacaleras españolas era inherente a su creación, y la significación de las preexistencias condicionaba la espacialidad del proyecto de reconversión fabril (Sobrino, 2011, p. 91).

\section{La dimensión productiva-espacial: topología del proceso industrial tabacalero}

Las Fábricas de Tabacos en España se caracterizaron por una constante evolución y complejización de sus espacios debido a las constantes reformas que sufrieron con el devenir del tiempo. De esta forma, se generó una interesante situación en la yuxtaposición de contrarios a través de una dualidad de lenguajes, desde el monumental inicial que manifestaba una voluntad de fuerte permanencia, hasta las tipologías constructivas propias de la industrialización que surgían en respuesta a las demandas del programa de necesidades productivo, caracterizadas por una cierta improvisación y una mutabilidad propia de las dinámicas industriales (Venturi, 1966) ${ }^{2}$. Igualmente, se debe destacar la distinción de dos periodos muy significativos dentro de la historia de la producción tabacalera en España: la primera fase de producción manufacturera con tintes preindustriales y la época impulsora de la mecanización de todas las fases productivas con la reestructuración de las fábricas en términos de renovación técnica y organizativa, instaurando una racionalización de la producción y del espacio fabril 3 .

El proceso productivo constituía un elemento conector de los distintos espacios fabriles en una arquitectura caracterizada por una cierta indeterminación programática debida al origen manufacturero de la actividad. Conformado por tres fases fundamentales, la localización de las mismas se realizaba siguiendo una gradación vertical, de forma que a medida que se ascendía en altura, la labor se volvía más refinada. De este modo, se ubicaban en planta baja aquellas tareas que generaban más desperdicios, mientras que las plantas superiores se reservaban a los talleres de liado y empaquetado por su mayor diafanidad y mejores condiciones de ventilación e iluminación. Pese a la racionalización del proceso y la sofisticación de las técnicas, estas tres fases productivas mantendrían a lo largo del tiempo tanto su localización en la fábrica como su marcada división.

Sin embargo, la obsolescencia prematura de las primeras fábricas de tabacos quedó patente con las diversas reformas motivadas por la puesta en marcha de la mecanización y los sucesivos planes de renovación. La incapacidad de estas arquitecturas de satisfacer las necesidades concretas que requería la modernización de la producción

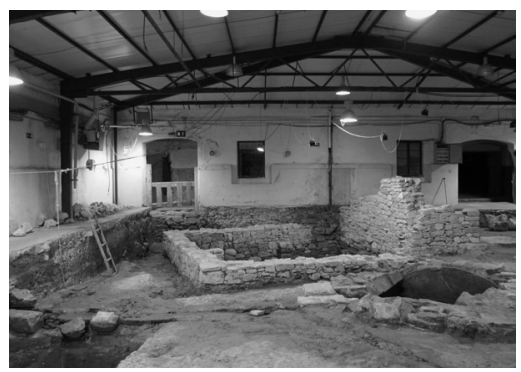

6. La complejidad y contradicción en la arquitectura de las Fábricas de Tabacos en España: patio central de la tabacalera de Gijón tras las excavaciones arqueológicas de 2006. Fuente: fotografía de la autora (2012).

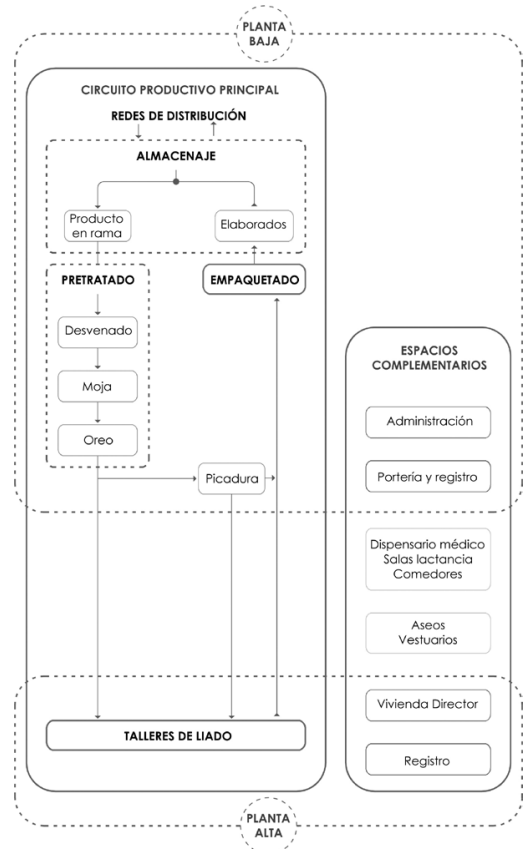

7. Esquema general de la relación topológica de los espacios productivos tabacaleros. Fuente: elaboración propia (2015). 


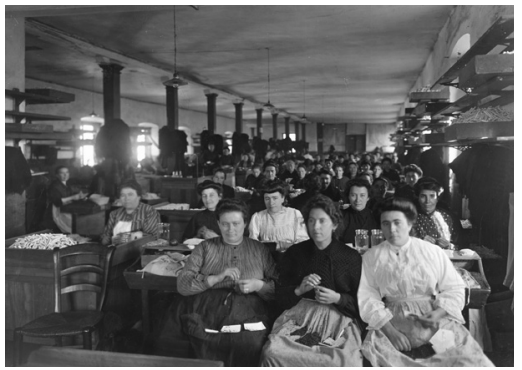

8. Cigarreras en el taller de Cigarros Superiores de la Fábrica de Tabacos de Gijón. Fuente: Fotografía de Julio Peinado (1909), custodiada en la Fototeca de Asturias.

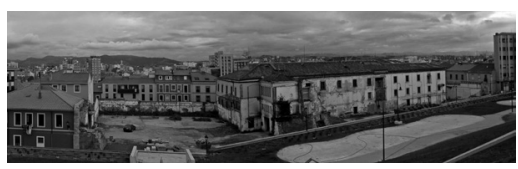

9. La Fábrica de Tabacos de Gijón a la espera de su recuperación para la ciudadanía.

Fuente: fotografía de la autora (2013). se manifestó en las limitaciones espaciales que afectaban tanto a las condiciones de habitabilidad y salubridad de los talleres, como a la disponibilidad de espacio acorde a la nueva escala productiva. Por tanto, a los problemas endémicos que presentarían este tipo de arquitecturas por sus carencias y dificultades en la adaptación a la evolución industrial, se uniría también la problemática que supondría su ubicación urbana en tejidos no aptos para la abultada circulación de materia prima y producto hacia los centros de distribución y producción. Como contrapunto a la ventaja inicial que supuso la adaptación de espacios preexistentes, la insostenibilidad económica de esta práctica ya se hizo evidente a finales del s.XIX.

\section{La dimensión humana: la cigarrera y espacio de trabajo}

La presencia de la mujer como trabajadora de las fábricas tabacaleras influiría en los espacios productivos como ambientes de fuerte feminización. De esta forma, se observa cómo durante la primera etapa manufacturera el propio espacio de trabajo, en su carácter de contenedor, servía en ocasiones como comedor, guardería o sala de lactancia. Esta situación de indefinición programática fue remitiendo con la introducción de las nuevas medidas organizativas de la Compañía Arrendataria de Tabacos, encaminadas a la resolución de las carencias experimentadas en las décadas precedentes y a erradicar el absentismo laboral de gran número de operarias que se ausentaban de sus puestos para atender sus obligaciones domésticas ${ }^{4}$.

La incipiente mecanización condicionaría el espacio de trabajo en la disminución del número de cigarreras necesarias para la producción y el aumento de personal masculino encargado de las tareas de asistencia técnica de la maquinaria. No obstante, este hecho no impidió que históricamente se mantuviese una mayoría de empleo de mano de obra femenina. El cambio de la balanza ocupacional tras la mecanización conllevaría a la aparición de espacios auxiliares marcados por la separación de género. Esta circunstancia tiene su explicación en la mejora de los servicios de la fábrica con la progresiva mecanización de las labores que coadyuvaría a la racionalización del interior y a una mejora considerable en términos de habitabilidad y confort, destinando los espacios sobrantes a funciones auxiliares para el personal como comedores, servicios higiénicos y vestuarios.

La polarización de la fábrica entre el área productiva y la zona de representatividad constituida por las oficinas administrativas y la residencia del director, manifestaba espacialmente la jerarquización de la unidad fabril. De igual forma, la fuerte coerción del espacio tabacalero como instrumento de control de las operarias condicionaba la circulación de las mismas en el interior de la fábrica, y a través del establecimiento de un único acceso en el que, a modo de exclusa, se llevaba a cabo un riguroso control. Precisamente, los registros abusivos en la entrada y salida de la fábrica eran motivo frecuente de protestas y revueltas por parte de las cigarreras. 
Por otro lado, uno de los aspectos más notables de la contextualización de la cigarrera en su espacio de trabajo era la extensión de la vida doméstica al ámbito laboral y viceversa. En muchos casos, la proximidad de las viviendas al entorno de la fábrica facilitaba la transferencia del rol femenino entre ambos espacios: la mujer como elemento aglutinador del ámbito doméstico, en su incorporación a la vida laboral, debía simultanear sendas labores. Además, el ambiente fabril tabacalero favorecía una suerte hermanamiento y fuerte sentimiento de comunidad entre compañeras -que frecuentemente eran, a su vez, vecinas y familiares-, coadyuvando a la formación de una conciencia identitaria que traspasaba los límites de la fábrica y que conformó una memoria colectiva que aún perdura (Candela, 1997 y Lanceta, 2013).

\section{La dimensión patrimonial: conclusiones sobre las tabacaleras como espacio de reflexión y oportunidad}

Actualmente, la condición urbana de las fábricas tabacaleras, unida al abandono de muchas de ellas y a su titularidad pública, ha convertido estos inmuebles en espacios de oportunidad para acometer proyectos que den servicio a la sociedad, susceptibles de consideración patrimonial como vestigios de una importante industria en su significación histórico-cultural. Muchos de los establecimientos fabriles tabacaleros, cuyo cierre sobrevino fundamentalmente en la primera década del S.Xxi, han sido rehabilitados con mayor o menor fortuna, adoptando nuevos usos a través de intervenciones contemporáneas. Sin embargo, la actual coyuntura económica dio al traste con muchos de los proyectos de reutilización y preservación de las Fábricas de Tabacos en España, abocando a los inmuebles afectados al abandono y a una degradación material en progresivo aumento.

En el presente trabajo se han analizado los rasgos arquitectónicoespaciales, identitarios y comunes, de los establecimientos tabacaleros en España a través de un enfoque que atiende a las dimensiones multiescalares que les caracterizan como patrimonio industrial arquitectónico. A la luz de esta argumentación se persigue incidir en la importancia que tiene el estudio del elemento fabril como documento histórico y base proyectual de las intervenciones a acometer en este conjunto de elementos industriales que, actualmente, se encuentran recuperados parcialmente, con parte de sus espacios en desuso e infrautilizados o, directamente, en estado de abandono. A través del estudio de sus características fundamentales arquitectónico-espaciales, la realidad industrial se convierte en un escenario más en el que transcurre nuestro presente, permitiendo la preservación de su memoria colectiva de forma figurada mediante una recuperación arquitectónica coyuntural a nuestro entendimiento de la intervención contemporánea en el patrimonio. 
$1 \rightarrow$ La separación entre la significación exterior de la fachada y la compleja realidad interior del espacio productivo en las Fábricas de Tabacos en España dio lugar a una tensión dialéctica que se alinea con la conceptualización de "automonumento" y "lobotomización arquitectónica" de la obra de Koolhaas.

Esta dualidad se transfirió al papel que adquirieron arquitectos e ingenieros en la concepción proyectual: mientras que el arquitecto se ocupaba del diseño compositivo del lienzo exterior, el ingeniero ostentaba la autoría de la práctica totalidad del proyecto de organización espacial del conjunto.

$2 \rightarrow$ La realidad particular de las Fábricas de Tabacos en España comparte

algunas de las características señaladas por Robert Venturi como "niveles de contradicción" en la tensión dialéctica entre arquitectura y espacio productivo. $3 \rightarrow$ A finales del S.XIX se plantea la necesidad de una transformación de las tabacaleras españolas debido a las carencias que presentaban para el desarrollo de una moderna actividad productiva y, no pudiendo asumir el Estado los costes y gestión de dicha transformación, se procedió en 1887 a la cesión del arriendo del monopolio del tabaco a la Compañía Arrendataria de Tabacos. Las reformas tendrían continuidad en 1945 con la sociedad Tabacalera Compañía Gestora del Monopolio de Tabacos y Servicios Anejos, que completaría el proceso de mecanización. $4 \rightarrow$ De esta forma, a lo largo del S.XIX surgirían diversos proyectos a modo de obra social por parte de la Renta de Tabacos, como el Asilo de Lactancia y las Escuelas de Párvulos concebidos por Ramón de La Sagra en Madrid - de los que sólo se realizaron las segundas- o el Asilo de Lactancia que se construyó frente a la nueva Fábrica de Tabacos de Valencia a principios del S.XX.

\section{Referencias bibliográficas}

Alonso Álvarez, L. (2001) Las tejedoras del humo. Historia de la Fábrica de Tabacos de A Coruña (1804-2000), Vigo: A Nosa Terra y Fundación Altadis.

Arias González, L. y Mato Díaz, A. (2005) Liadoras, cigarreras y pitilleras: la Fábrica de Tabacos de Gijón (1837-2002), Madrid: Dirección de Comunicación de Altadis.

Campos Luque, C. (2004) Las cigarreras malagueñas: tecnología, producción y trabajo en la Fábrica de Tabacos de Málaga, Madrid: Fundación Altadis. Candela Soto, P. (1997) Cigarreras madrileñas: trabajo y vida (1888-1927), Madrid: Tecnos.

Fièvre, L. (2004) Les manufactures de tabacs et d'allumettes. Morlaix, Nantes, Le Mans et Trélazé (XVIII $-X X^{e}$ siècles), PU Rennes.

-

Hernando, J. (1989) La arquitectura industrial. En Arquitectura en España 1770 - 1900, (pp. 353 - 371), Madrid: Cátedra.
Koolhaas, R. (1978, ed. 2004) Delirio de Nueva York, Barcelona: Gustavo Gili. Lanceta Aragonés, T. (2013) Mujeres e industria tabaquera en Alicante, del Bullent.

-

Morales Sánchez, J. (1991) La Real Fábrica de Tabacos: arquitectura, territorio y ciudad en la Sevilla del siglo XVIII, Sevilla: Fundación Fondo de Cultura de Sevilla, D.L. Tesis doctorales, Colección "Focus"; n. 2. Muiños Villaverde, M. J. y Perol Grau, V. (2008) La realidad de un Mito. La Fábrica de Tabacos de Tarragona (1932 - 2007), Fundación Altadis.

Rodríguez Gordillo, J. M. (2002) La difusión del tabaco en España: diez estudios, Sevilla: Universidad de Sevilla.

Selvafolta, O. (1985) El espacio del trabajo (1750-1910). Debats. Institució Alfons El Magnánim. Institució Valenciana d'Estudis i Investigació, septiembre, 13, 52-69.
Sobrino Simal, J. (2011) La Real Fábrica de artillería de Sevilla: hacia un espacio patrimonialmente activo y de producción creativa. Ábaco. Revista de cultura

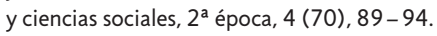

Teixidor de Otto, M. J. y Hernández Soriano, T. (2000) La Fábrica de Tabacos de Valencia: Evolución de un Sistema Productivo (1887-1950), Valencia: Universitat de València.

Venturi, R. (1966, ed. 2012) Complejidad y contradicción en la arquitectura, Barcelona: Gustavo Gili. 